\title{
Longitudinal Imperfections on Thin Walled Cylindrical Shells
}

\author{
Mahyar Maali ${ }^{1}$, Abdulkadir Cuneyt Aydın ${ }^{1 *}$, Hossein Showkati ${ }^{2}$, Seied Mahdi Fatemi ${ }^{3}$ and Merve Sagıroglu ${ }^{4}$ \\ ${ }^{1}$ Faculty of Engineering, Department of Civil Engineering, Ataturk University, Erzurum, Turkey \\ ${ }^{2}$ Department of Civil Engineering, Urmia University, Urmia, Iran \\ ${ }^{3}$ Department of Civil Engineering, Islamic Azad University, Maragheh Branch, Iran \\ ${ }^{4}$ Faculty of Engineering, Department of Civil Engineering, Erzurum Technical University, Erzurum, Turkey
}

\begin{abstract}
Buckling and post-buckling are among the most important failure factors in thin walled structures. The loadcarrying behavior of cylindrical thin-walled shell structures under external pressure load is strongly dependent upon the nature and magnitude of the initial imperfections. These imperfections are invariably caused by an assortment of manufacturing processes like installing or welding. One of the most important imperfections caused by welding that has been reported to have an essential detrimental effect on the buckling resistance of these shells under external pressure load is longitudinal imperfections. Buckling and post buckling capacity of the shells depend on the H/R and $t / R$ ratios $(H$ the height, $R$ the radius and $t$ the thickness of a cylindrical shell). The present work discusses the finiteelement models labeled as SS (Shallow Slim), DS (Deep Slim), ST (Shallow Thick) and DT (Deep Thick). The samples of first group are modified to include a line longitudinal imperfection, amplitudes of $0.5 \mathrm{t}, 1 \mathrm{t}, 2 \mathrm{t}$, 3t, 4t and $8 \mathrm{t}$ in depth ( $t$ is the thickness of cylindrical shell). The results presented are in agreement with international codes and theories concerning buckling.
\end{abstract}

Keywords: Buckling; Cylindrical shells; Longitudinal imperfection; Non-linear analysis; Perfect model

Notations: E: Young's modulus; R: Radius of cylinder; L: Height of cylinder; t: Thickness of cylinder; n: Number of approximate waves

\section{Introduction}

Buckling and collapse are two structures of thin-walled cylindrical shells. Buckling of a cylindrical shell depends on the scores of variables, for example, the geometric properties, the material properties and the type of the applied load. Thin-walled circular cylindrical shells are very common in civil engineering applications, such as tanks, silos, offshore and marine structures, ship industrial chemical plants [14]. Rolling and construction have much effect on buckling and postbuckling capacity of the cylindrical shells. The buckling capacity of the cylindrical shell depends greatly on the following two geometric rations: $H / R$ (height to the radius of shell), and the slenderness $t / R$ (thickness to the radius of shell) [5]. There is a lot of literature devoted to the analysis of geometrically imperfect cylindrical shells. In 1995, Showkati and Ansourian [6] investigated the influence of primary boundary conditions on the buckling of shallow cylindrical shells under uniform external pressure [6]. Donnell calculated the buckling load for a cylindrical shell and obtaining a theoretical load on the cylindrical shell under hydrostatic pressure [6]. In 2001, Pircher et al. [7] studied the shape of circumferential weld-induced imperfections in thin-walled steel silos and tanks, and introduced several shapes of circumferential imperfections, which occurs in real conditions. Many researchers studied the buckling resistance of cylindrical shells through nonlinear finite-element methods. Hornug and Saal [8] searched on real-size tanks to examine the effects of imperfections on the buckling load of cylindrical shells. Schneider and Brede [9] studied the effects of geometric imperfections on the buckling resistance of cylindrical shells. Maali et al. [10] studied the buckling behavior of conical shells and showed the stiffening effect of weld-induced imperfections on the buckling strength. In 2013, Fatemi et al. [5] conducted experiments on imperfect cylindrical shells under uniform external pressure and showed the detrimental effects on the buckling of weld-induced geometric imperfections. Niloufari et al. [11] conducted experiments on imperfect steel tanks under hydrostatic pressure and showed the detrimental effects on buckling and post buckling of weld-induced geometric imperfections. Additionally, Eurocode 3, ECCS and DINI18800 [12-18] have all set limitations for rolling- and welding-induced imperfections.
In this study, not only presents the longitudinal overall imperfection, which is same circumferential imperfection in Picher's paper [7], but also presents the effects of imperfection on the buckling of circular cylindrical shells under external uniform pressure with different $H / R$ and $\mathrm{R} / \mathrm{t}$ ratios.

\section{Materials and Methods}

The present study considers 28 cylindrical shells in four groups with different $H / R$ and $t / R$ ratios. All models contained one perfect model with the remaining models having imperfections with amplitudes of $t$ ( $t$ the thickness of cylindrical shell). Average yield and failure stresses were obtained 194.2MPa and 325.5MPa, respectively. Young's modulus calculated as $200 \mathrm{GPa}$ and Poisson's ratio was obtained as 0.28 [5]. All models were simply supported and analyzed by ABAQUS software. The results of the buckling were not only compared to the results reported in previous and international codes, but also compared with the perfect model.

\section{Size and imperfect shape}

According to previous research on thin-walled cylindrical shells, and also international codes have all set limitation for rolling and welding induced imperfection [12-18]. We decided to choose the different thickness-to-radius ratio ( $/ \mathrm{R})$ within the range of 0.001 $0.0033[6]$.

Four groups of models were tested for this study. The first group is SS (Shallow Slim labeled specimens labeled as SSP, SS0.5, SS1, SS2, SS3, SS4, and SS8. The second group of specimens is DS (Deep Slim) ones labeled as DSP, DS0.5, DS1, DS2, DS3, DS4, and DS8. The third

*Corresponding author: Abdulkadir Cüneyt Aydın, Faculty of Engineering Department of Civil Engineering, Ataturk University, Erzurum-25240, Turkey, Tel: +90 44223147 81; E-mail: acaydin@atauni.edu.tr

Received January 06, 2018; Accepted April 20, 2018; Published April 26, 2018

Citation: Maali M, Aydın AC, Showkati H, Fatemi SM, Sagıroglu M (2018) Longitudinal Imperfections on Thin Walled Cylindrical Shells. J Civil Environ Eng 8: 308. doi: 10.4172/2165-784X.1000309

Copyright: (c) 2018 Maali M, et al. This is an open-access article distributed under the terms of the Creative Commons Attribution License, which permits unrestricted use, distribution, and reproduction in any medium, provided the original author and source are credited. 
group labeled ST (Shallow Thick) labeled as STP, ST0.5, ST1, ST2, ST3, ST4, and ST8. The fourth group is named as DT (Deep Thick) with the specimens labeled as DTP, DT0.5, DT1, DT2, DT3, DCT4 and DT8. Table 1 provides the detailed geometry and slenderness ratios of the specimens. All models were considered as simply supported and analyzed by ABAQUS software in accordance with the past research [27]. Therefore, in this study, we selected good geometric imperfection, which occurs in real conditions. The imperfection type is as shown in Figure 1.

The imperfection is composed of a four quarter-circle compound with a radius of $\mathrm{Bt}$ ( $\mathrm{Bt}$ is the depth of the imperfection).

\section{The Buckle and Riks analyses}

The buckling load can be obtained by the liner (Eigen value) and nonlinear analyses in the Abaqus software. As a result of static linear analysis and internal forces, the stiffness matrix of the structure and the Eigen value mode can be obtained from the equilibrium equations. The linear method simply calculates the overall distribution of stress and the relative displacement. Furthermore, the buckling shape mode and factor load offered by the linear method can be obtained [19]. The nonlinear methods calculate the real displacement and stress. Therefore, the Arc length (Riks) method is used, as a proper method for solving the nonlinear buckling problem and to determine the load-displacement path within a more realistic way. By this way, the main characteristics are considered as nonlinear, unlike the Eigen value method. The most important point in this method is to shorten the maximum arc length, when the load amounts become negative and the analyses become unstable after arriving to bifurcation point.

\section{Theoretical analyses}

The analytical solutions given here ignore the effect of pre-buckling rotations, and assume the cylinder as free to stretch longitudinally. The simplified version of the Donnell Stability equations (1) in coupled form and for uniform pressure $\mathrm{q}$ is [6]:

$D \Delta^{8} w+\frac{E t}{R^{2}} W_{, X X X X}+\frac{1}{R} q \Delta^{4} W_{, \theta \theta}=0$

Where $\mathrm{D}=\mathrm{Et}^{3} / 12\left(1-\mathrm{v}^{2}\right), \mathrm{w}=$ radial deflection, $\mathrm{x}=$ meridional distance and $\theta=$ circumferential angle. Symmetry considerations imply periodicity and the general solution in terms of the four constants of integration is given by:

$w=\left(c_{1} \cdot \sin \lambda x+c_{2} \cdot \cos \lambda x+c_{3} \cdot x+c_{4}\right) \sin n \theta$
Where $\lambda=m \pi /$ Land $m, n=1,2,3, \ldots$. The boundary conditions are used to solve the four constants. The case that is amenable to analytical solution is S-S, which corresponds to radial restraint at the two ends. Substitution of the conditions of zero radial deflection and moment at the ends and minimization of the buckling solution with respect to the wave numbers $\mathrm{m}$ and $\mathrm{n}$ leads to the solution $\mathrm{m}=1$ and:

$\mathrm{q}_{c r}=E \frac{t}{R}\left\{\frac{\left[\left(\frac{\pi R}{L}\right)^{2}+n^{2}\right]^{2}}{n^{2}} \frac{\left(\frac{t}{R}\right)^{2}}{12\left(1-v^{2}\right)}+\frac{\left(\frac{\pi R}{L}\right)^{4}}{{ }_{n}^{2}\left[\left(\frac{\pi R}{L}\right)^{2}+n^{2}\right]^{2}}\right\}$

This critical pressure is a function of $\mathrm{n}^{4}$ obtained following minimization of $\mathrm{q}_{\mathrm{cr}}$ as:

$n^{6} \frac{\left(n^{2}-1\right)^{2}}{\left(n^{2}-2 / 3\right)}=36 \pi^{4}\left(1-v^{2}\right)\left(\frac{R}{L}\right)^{4}\left(\frac{R}{t}\right)^{2}$

Some simplification is possible when $n^{2}$ is much greater than 1 , when $\mathrm{n}$ becomes:

$n=\sqrt[4]{\frac{6 \pi^{2} \sqrt{1-v^{2}}}{\left(\frac{L}{R}\right)^{2}\left(\frac{t}{R}\right)}} \approx 2.74 \sqrt{\frac{R}{L} \sqrt{\frac{R}{t}}}$

Except in the case of classical simple supports and a limited geometry, it is not generally possible to find analytical solutions for $\mathrm{n}$. In addition, a full numerical investigation of $\mathrm{n}$ under general boundary conditions has not been noted throughout the literature except possibly for the case of clamped supports at both ends. The case of elastic end
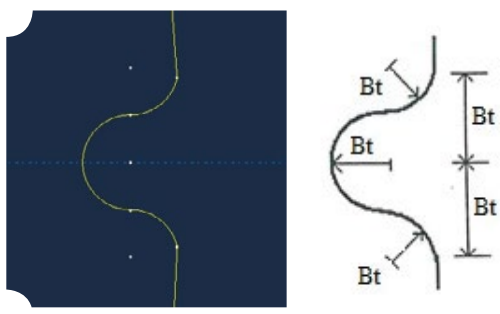

Figure 1: Shape of the imperfection

\begin{tabular}{|c|c|c|c|c|c|c|c|c|c|c|c|}
\hline Model & $\mathbf{R}(\mathbf{m m})$ & $\mathrm{t}(\mathrm{mm})$ & $H / R$ & $t / R$ & Mode & Model & $\mathbf{R}(\mathrm{mm})$ & $\mathbf{t}(\mathrm{mm})$ & $H / R$ & $t / R$ & Mode \\
\hline SSP & 300 & 0.5 & 1 & 0.002 & Perfect & STP & 300 & 0.6 & 1 & 0 & Perfect \\
\hline SS0.5 & 300 & 0.5 & 1 & 0.002 & $0.5 t^{*}$ & STO. 5 & 300 & 0.6 & 1 & 0 & $0.5 \mathrm{t}$ \\
\hline SS1 & 300 & 0.5 & 1 & 0.002 & $1 \mathrm{t}$ & $\mathrm{ST} 1$ & 300 & 0.6 & 1 & 0 & $1 \mathrm{t}$ \\
\hline SS2 & 300 & 0.5 & 1 & 0.002 & $2 t$ & ST2 & 300 & 0.6 & 1 & 0 & $2 t$ \\
\hline SS3 & 300 & 0.5 & 1 & 0.002 & $3 t$ & ST3 & 300 & 0.6 & 1 & 0 & $3 t$ \\
\hline SS4 & 300 & 0.5 & 1 & 0.002 & $4 \mathrm{t}$ & ST4 & 300 & 0.6 & 1 & 0 & $4 \mathrm{t}$ \\
\hline SS8 & 300 & 0.5 & 1 & 0.002 & $8 \mathrm{t}$ & ST8 & 300 & 0.6 & 1 & 0 & $8 t$ \\
\hline DSP & 300 & 0.5 & 1.5 & 0.002 & Perfect & DTP & 300 & 0.6 & 1.5 & 0 & Perfect \\
\hline DS0.5 & 300 & 0.5 & 1.5 & 0.002 & $0.5 \mathrm{t}$ & DT0.5 & 300 & 0.6 & 1.5 & 0 & $0.5 \mathrm{t}$ \\
\hline DS1 & 300 & 0.5 & 1.5 & 0.002 & $1 \mathrm{t}$ & DT1 & 300 & 0.6 & 1.5 & 0 & $1 \mathrm{t}$ \\
\hline DS2 & 300 & 0.5 & 1.5 & 0.002 & $2 \mathrm{t}$ & DT2 & 300 & 0.6 & 1.5 & 0 & $2 \mathrm{t}$ \\
\hline DS3 & 300 & 0.5 & 1.5 & 0.002 & $3 t$ & DT3 & 300 & 0.6 & 1.5 & 0 & $3 t$ \\
\hline DS4 & 300 & 0.5 & 1.5 & 0.002 & $4 \mathrm{t}$ & DT4 & 300 & 0.6 & 1.5 & 0 & $4 \mathrm{t}$ \\
\hline DS8 & 300 & 0.5 & 1.5 & 0.002 & $8 \mathrm{t}$ & DT8 & 300 & 0.6 & 1.5 & 0 & $8 \mathrm{t}$ \\
\hline
\end{tabular}

*Imperfection depth 
restraint is not considered throughout this paper, although this will be the subject of a subsequent paper [6].

The follower load effects have not been taken into account in this investigation. It has been reported that, in long and thick cylinders, the effect is to reduce the critical pressure by a few percent when compared with solutions that consider a constant load direction. Long and thick cylinders are also less imperfection sensitive. The range of parameters is considered in this paper, such that the neglect of the follower load effect leads only to very small errors except for the case where $n=2$. The cases $n=0$ and $n=1$ are special cases of axisymmetric, beam-like or torsional buckling. In the case of external pressure loading, $\mathrm{n}$ has a minimum value of 2 , which is the ovalization mode in very long, or long and thick cylinders, or short cylinders with special boundary conditions. In a mathematical treatment of buckling, when the pressure is minimized with respect to $n, n$ is assumed to be a continuous variable, although is in fact an integer value. In this case, the waves are of the same length, while, under non-uniform loading, the modal pattern is not regular for wind pressure loading [6].

For other boundary conditions, numerical methods are generally required. When the geometric parameter $\sqrt{\left(1-v^{2}\right) L^{2}} /(R t)$ obtained as one (very short cylinders), the behavior is like a long, flat, rectangular plate in uniaxial compression for most boundary conditions. When the pressure is 'hydrostatic', the equivalent plate is bi-axially compressed. The geometric analogy is that the plate thickness is also $t$, the length a; corresponds to $2 \pi R$, and the width $b$ to $L$. The results for these very short cylinders are not reproduced here, but elsewhere [6].

The critical buckling load of thin-walled cylindrical shells is estimated by equation (6), which was obtained from Donnell's exact solution with some simplifications. This is offered for an ideal geometric form [2].

\section{$P_{c r=} 0.92 E\left[{ }_{L}^{R}\left(\begin{array}{l}t \\ R\end{array}\right)^{2.5}\right)$}

Where $\mathrm{E}$ is the Young's modulus, $\mathrm{t}$ is the thickness, $\mathrm{R}$ is the radius and $\mathrm{L}$ is the height. Table 2 presents the results from the Donnell equation and the number of circumferential buckling waves, calculated through approximate equation (5) for the perfect models.

\section{Finite-element mesh}

We select S4R element and 6 degrees of freedom for each point, which is especially shell by past research and Abaqus software laboratory. It's designed for linear and nonlinear analyses and it is a useful tool for large deformities [20,21]. In this study, the SSP and DTP Models are selected, and the ideal mesh is obtained through linear buckling load analyses when an ideal mesh is obtained for SSP and DTP models, that mesh can be better for all models. According to analysis of buckling load, a proper mesh is obtained with an approximate global size as 0.005 . Furthermore, we selected one point in each $5 \mathrm{~mm}$ on cylindrical shell for mesh section. Figures 2 and 3 and Tables 3 and 4 present the selection of the mesh for SSP and DTP models. In addition, we shortened distance meshes to half of another point distance in imperfection location. Thus, the accuracy level of the analysis is increased. We also used sweep technical mesh with quad-dominated shape in this study. This technique causes coordinating and adapting of the structure to meshing formed.

All models analyzed under uniform external pressure load and analyzed by ABAQUS software. All models were considered simply supported while they assumed the third displacement components are closed and the third rotation components are opened.

\section{Results of Buckle Analysis (Linear Analysis)}

As mentioned in most articles where cylindrical shells under pressure load have been investigated, we used in equation 6 for normalizing the result of a perfect model. Table 2 presents the results of the Donnell equation for the Abaqus models. There are no equations for imperfection models. Furthermore, we have done linear analysis to find wave numbers for each group. Tables 5-8 present the linear analysis for perfect and imperfect models and wave number for each model. Figures 4-7 present the result of linear analysis and wave buckling for each group.

\section{Comparison between the results of the linear Analysis of the SS and DS groups of models with the ratio of $t / R$ equal to 0.0016}

The results of buckling analysis were 1.54 times larger than the result

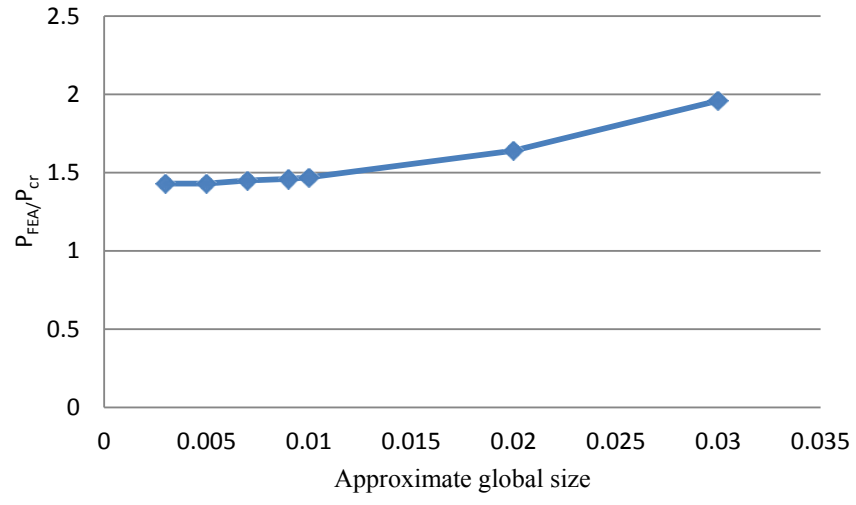

Figure 2: Results of the approximate global size for the SSP model.

\begin{tabular}{|c|c|c|c|c|}
\hline Model & SSP & DSP & STP & DTP \\
\hline $\mathrm{P}_{\mathrm{cr}}$ - Eq. 6 $(\mathrm{kPa})$ & 20.9 & 13.9 & 32.9 & 21.9 \\
\hline Eq.5 Approx. number of waves & 14 & 11 & 13 & 10 \\
\hline
\end{tabular}

Table 2: Results of the critical buckling load and wave equation.

\begin{tabular}{|c|c|c|c|}
\hline $\begin{array}{c}\text { Approximate } \\
\text { global size }\end{array}$ & $\begin{array}{c}\text { Eq. 6 } \\
\mathbf{( k P a )} \mathbf{P}_{\mathbf{c r}}\end{array}$ & $\begin{array}{c}\text { Linear buckling load obtained by } \\
\left.\mathbf{A b a q u s}(\mathbf{K P a}) \mathbf{(}_{\text {FEA }}\right)\end{array}$ & $\begin{array}{c}\left.\mathbf{( P}_{\mathbf{P}_{\text {FEA }}}\right) / \\
\mathbf{( P}_{\mathrm{cr}} \mathbf{)}\end{array}$ \\
\hline 0.03 & 20.86 & 40.872 & 1.96 \\
\hline 0.02 & 20.86 & 34.207 & 1.64 \\
\hline 0.01 & 20.86 & 30.755 & 1.47 \\
\hline 0.009 & 20.86 & 30.554 & 1.46 \\
\hline 0.007 & 20.86 & 30.194 & 1.45 \\
\hline 0.005 & 20.86 & 29.905 & 1.43 \\
\hline 0.003 & 20.86 & 29.716 & 1.43 \\
\hline
\end{tabular}

Table 3: Results of the buckling load for SSP model.

\begin{tabular}{|c|c|c|c|}
\hline $\begin{array}{l}\text { Approximate } \\
\text { global size }\end{array}$ & Eq. $6(\mathrm{kPa}) \mathrm{Pcr}$ & $\begin{array}{c}\text { Linear buckling load } \\
\text { obtained by Abaqus (KPa) } \\
\left(\mathrm{P}_{\mathrm{FEA}}\right)\end{array}$ & $\left(\mathbf{P}_{\mathrm{FEA}}\right) /\left(\mathbf{P}_{\mathrm{cr}}\right)$ \\
\hline 0.03 & 21.94 & 38.491 & 1.75 \\
\hline 0.02 & 21.94 & 34.371 & 1.57 \\
\hline 0.01 & 21.94 & 32.214 & 1.47 \\
\hline 0.009 & 21.94 & 32.084 & 1.46 \\
\hline 0.007 & 21.94 & 31.867 & 1.45 \\
\hline 0.005 & 21.94 & 31.707 & 1.44 \\
\hline 0.003 & 21.94 & 31.602 & 1.44 \\
\hline
\end{tabular}

Table 4: Results of the buckling load for DTP model. 
of the Donnell theory in the perfect models (without imperfection) which the result of linear analysis is inconsistent with the result of the Donnell theory and the result of linear analysis are conservative. Therefore, it is fitting that we use of the nonlinear analysis method (Riks method) for investigation buckling loads of cylindrical shells.

The theoretical buckling loads obtained from the Donnell theory from the SS and DS group models are in the range between 27-54 percent less than the results of linear analysis. Therefore, if we used linear analysis for investigation buckling load of perfect and imperfect cylindrical shell. The result of linear analysis is greater than 1.54 times the results from the Donnell theory.

According to Tables 5 and 6 , the imperfection depth is greater. The imperfect models ration to perfect models is the same as a stiffener. For example, the result of the Buckle analysis for SSP, SS2 and SS8 models is $29.905 \mathrm{KPa}, 29.425 \mathrm{KPa}$ and $29.933 \mathrm{KPa}$, respectively. These show that the buckling capacity is increased, and $8 \mathrm{t}$ imperfection can be used as a stiffener for cylindrical shells. As shown in Figures 4 and 5, axial number waves are the same as each other. The number of the wave is 1 and circumferential wave numbers are 16 and 13 for the SS and DS models, respectively. Figures 4 and 5 show the circumferential waves are disappeared between ranges of $2 \mathrm{t}-4 \mathrm{t}$ imperfections. Then, those are appearing in $8 \mathrm{t}$ imperfection, because of the $8 \mathrm{t}$ imperfection acts as a stiffener. There is a wave on an imperfection section in all models without SS8 and DS8 models are the same as a stiffener. We obtained the number of circumferential waves by 5 equations, which are shown in Table 2. The exact number of waves can be obtained by addition of $5^{\text {th }}$ and $2^{\text {nd }}$ equations.

\begin{tabular}{|l|c|c|c|c|c|c|c|}
\hline Model & SSP & SS0.5 & SS1 & SS2 & SS3 & SS4 & SS8 \\
\hline Linear (buckle) (KPa) & 29.91 & 29.887 & 29.82 & 29.43 & 28.92 & 29.43 & 29.93 \\
\hline Percent to perfect (\%) & - & -0.06 & -0.295 & -1.631 & -3.42 & -1.63 & 0.094 \\
\hline Percent to Eq. 6 (\%) & 30.25 & 30.22 & 30.04 & 29.11 & 27.86 & 29.11 & 30.31 \\
\hline Axial wave & 1 & 1 & 1 & 1 & 1 & 1 & 1 \\
\hline Circumferential wave & 16 & 16 & 16 & 16 & 16 & 16 & 16 \\
\hline
\end{tabular}

Table 5: Results of the linear analysis of SS models.

\begin{tabular}{|l|c|c|c|c|c|c|c|}
\hline Model & DSP & DS0.5 & DS1 & DS2 & DS3 & DS4 & DS8 \\
\hline Linear (buckle) (KPa) & 20.09 & 20.076 & 20.05 & 19.95 & 19.7 & 19.39 & 29.93 \\
\hline Percent to perfect (\%) & - & -0.045 & -0.154 & -0.671 & -1.98 & -3.595 & 32.9 \\
\hline Percent to Eq. 6 (\%) & 30.74 & 30.71 & 30.64 & 30.28 & 29.37 & 28.25 & 53.53 \\
\hline Axial wave & 1 & 1 & 1 & 1 & 1 & 1 & 1 \\
\hline Circumferential wave & 13 & 13 & 13 & 13 & 13 & 13 & 13 \\
\hline
\end{tabular}

Table 6: Results of the linear analysis of DS models.

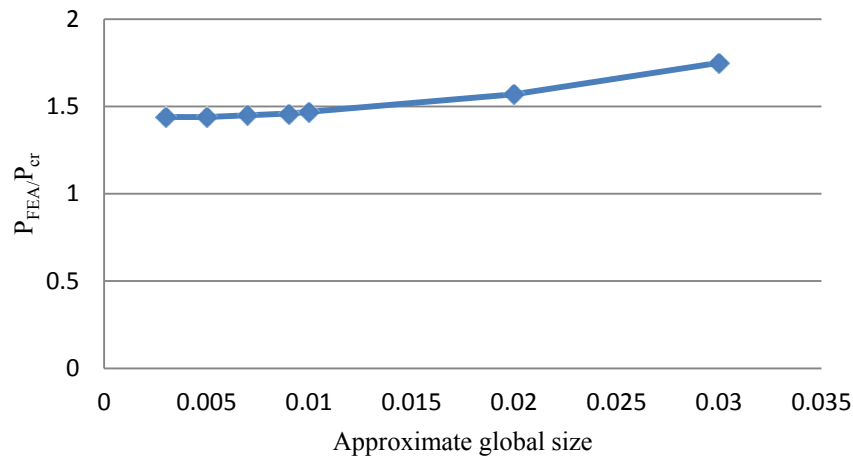

Figure 3: Results of the approximate global size for the DTP model.

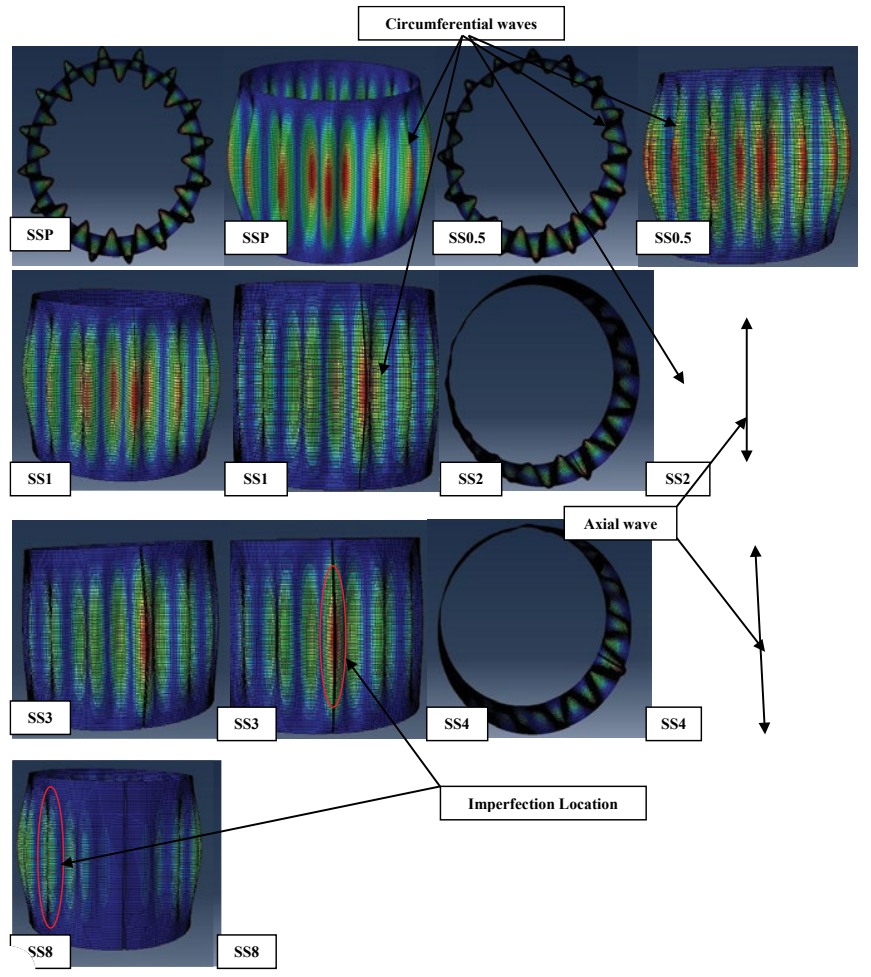

Figure 4: The buckling analysis for SS models.

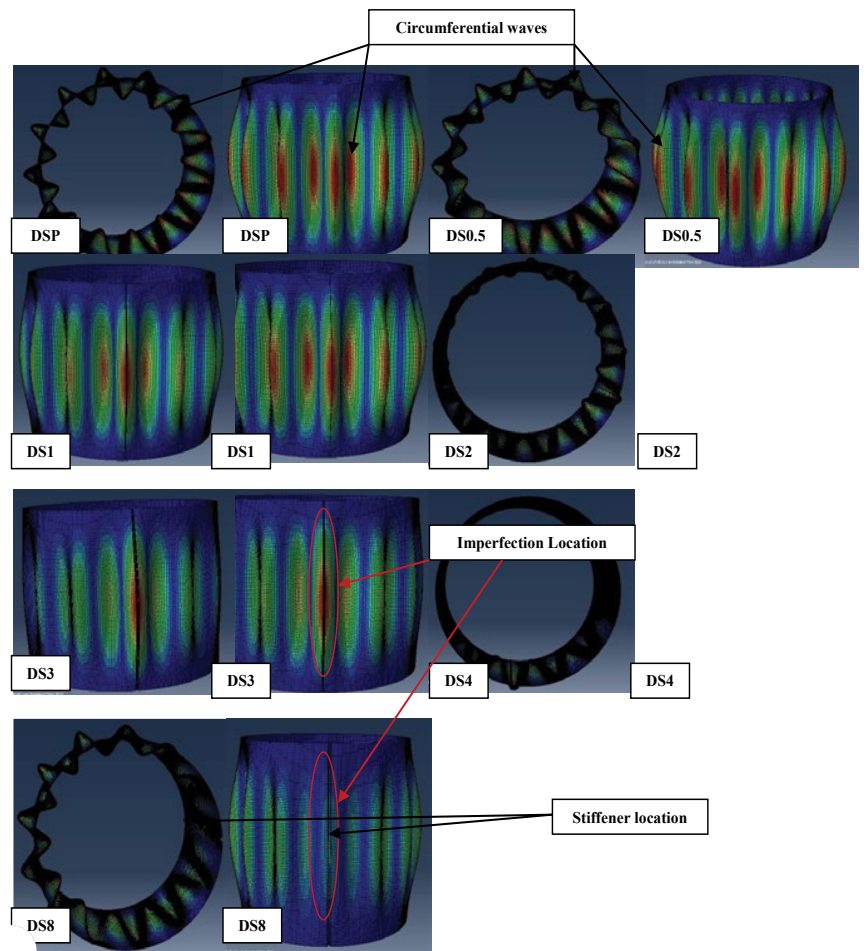

Figure 5: The buckling analysis for DS models.

\section{Comparison between the results of the linear Analysis of the} ST and DT groups of models with the ratio of $t / R$ equal to 0.002

The results of buckling analysis showed 1.32 times larger than the result from the Donnell theory in the perfect models (without 
imperfection), where the result of linear analysis is inconsistent with the result from the Donnell theory. The results of linear analysis are conservative. Therefore, the nonlinear analysis method (Riks method) is a proper way for investigating buckling loads of cylindrical shells.

The theoretical buckling loads, obtained with the Donnell theory from ST and DT group models, are in the range between 27-32 percent less than the linear analysis. Therefore, the linear results are 1.32 times greater than the Donnell theory, for the investigation of perfect and imperfect cylindrical shells buckling load.

According to Tables 7 and 8, imperfection models are acted as stiffened ones. For example, the result of the Buckle analysis for DTP, DT2 and DT8 models is $31.707 \mathrm{KPa}, 31.348 \mathrm{KPa}$ and 31.810 $\mathrm{KPa}$, respectively. These show that the buckling capacity is increased. Thus, $8 \mathrm{t}$ imperfection can be used as a stiffener, and it is useful for cylindrical shells. As seen in Figures 6 and 7, axial number waves are

\begin{tabular}{|c|c|c|c|c|c|c|c|}
\hline Model & STP & ST0.5 & ST1 & ST2 & ST3 & ST4 & ST8 \\
\hline Linear (buckle) $(\mathrm{KPa})$ & 46.8 & 46.76 & 46.66 & 45.95 & 45.41 & 46.78 & 47 \\
\hline Percent to perfect (\%) & - & -0.068 & -0.302 & -1.857 & -3.06 & -0.045 & 0.41 \\
\hline Percent to Eq. 6 (\%) & 29.67 & 29.63 & 29.46 & 28.37 & 27.52 & 29.64 & 30 \\
\hline Axial wave & 1 & 1 & 1 & 1 & 1 & 1 & 1 \\
\hline Circumferential wave & 15 & 15 & 15 & 15 & 15 & 15 & 15 \\
\hline
\end{tabular}

Table 7: Results of the linear analysis of ST models.

\begin{tabular}{|c|c|c|c|c|c|c|c|}
\hline Model & DTP & DT0.5 & DT1 & DT2 & DT3 & DT4 & DT8 \\
\hline Linear (buckle) (KPa) & 31.71 & 31.69 & 31.63 & 31.35 & 30.77 & 30.38 & 31.8 \\
\hline Percent to perfect (\%) & - & -0.054 & -0.237 & -1.145 & -3.062 & -4.36 & 0.32 \\
\hline Percent to Eq. 6 (\%) & 30.8 & 30.76 & 30.64 & 30.01 & 28.68 & 27.78 & 31 \\
\hline Axial wave & 1 & 1 & 1 & 1 & 1 & 1 & 1 \\
\hline Circumferential wave & 12 & 12 & 12 & 12 & 12 & 12 & 12 \\
\hline
\end{tabular}

Table 8: Results of the linear analysis of DT models.

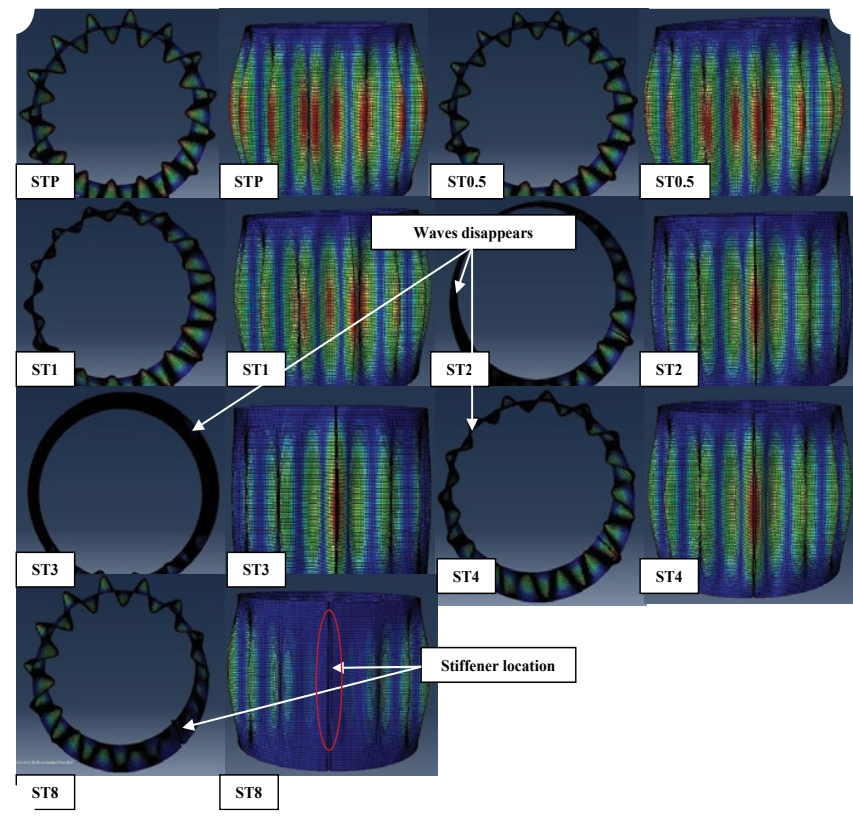

Figure 6: The buckling analysis for ST models.
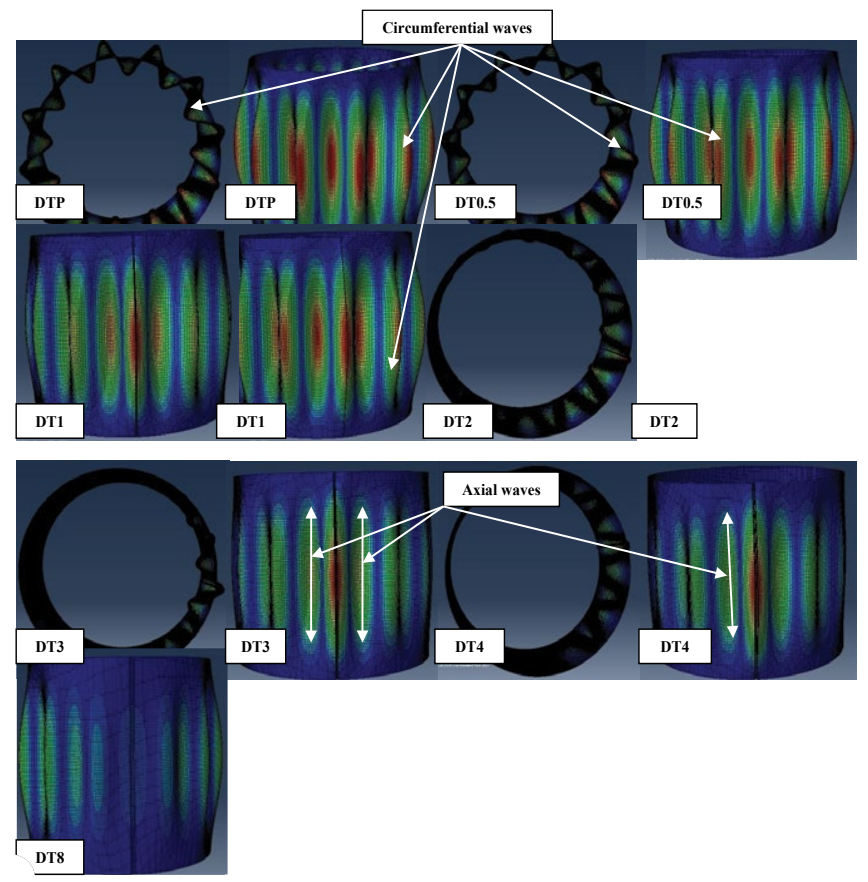

Figure 7: The buckling analysis for DT models.

the same as each other, and the wave number is 1 and circumferential wave numbers are 15 and 12 for the SS and DS models, respectively. Figures 4 and 5 show the circumferential waves, which are disappeared between ranges of $2 \mathrm{t}-4 \mathrm{t}$ imperfections. Then, those are appearing in $8 \mathrm{t}$ imperfection. Because of the $8 t$ imperfection, it acts as a stiffener. There is a wave on an imperfection section in all models except ST8 and DT8 models, which are the same as a stiffener. We obtained the number of circumferential waves by the $5^{\text {th }}$ equations which are shown in Table 2 . If we compare the results of equation 5 with imperfection models, we should add equation 5 to 2 to obtain correct number waves.

Comparison between the result of the linear analysis of all groups of models with the ratio of $t / R$ equal to 0.0016 and 0.002

While the values of $t / R$ between 0.0016 and 0.002 , the buckling loads obtained from the linear theory is 1.54 times greater than the Dunnel theory. The number of circumferential waves can be obtained by adding $5^{\text {th }}$ and $2^{\text {nd }}$ equations.

However, the imperfection depth is greater. The imperfections act as a stiffener in all groups. For example, $8 \mathrm{t}$ imperfection is as a stiffener, because the buckling load capacities in $8 \mathrm{t}$ imperfection models are greater than the other models in all groups. Furthermore, the height of the cylindrical $(\mathrm{H})$ is higher. So, the buckling load capacity is low. The $0.5 \mathrm{t}$ and $1 \mathrm{t}$ type imperfections are weaker and their effects low. Thus, $0.5 t$ and $1 \mathrm{t}$ type imperfections are neutral, and those are the same as the perfect models. The critical buckling load capacity occurs between $2 \mathrm{t}-3 \mathrm{t}$ type imperfections, which disappear in the range of all groups.

\section{Results of Riks Analysis (Non-linear)}

\section{Non-linear analysis of the SS and DS groups of models with the ratio of $t / R$ equal to 0.0016}

Table 9 presents the results of initial and collapse buckling to the Donnell theory for the perfect models. The comparison between the 
results of Eq. (6) and the results of the $\mathrm{t} / \mathrm{R}=0.0016$ models reveal that the obtained initial buckling load of the Riks analysis is $26 \%-36 \%$ greater than the Donnell theory. The buckling load for the collapse is 30\%-36\% greater than the Donnell theory. Therefore, if we want to obtain the non-linear buckling load from the Donnell theory for $\mathrm{t} / \mathrm{R}=0.0016$, we should multiply the Donnell theory with 1.36 .

Table 9, Figures 8 and 9 present the results of the initial buckling by Riks analysis for SS and DS models. Although the imperfection depth is greater, the imperfections act weaker, where a negative effect

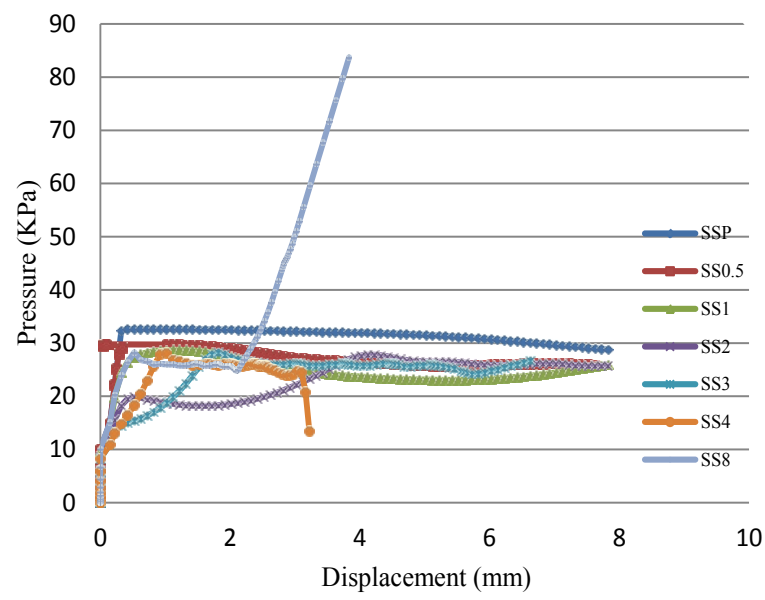

Figure 8: Load-displacement graphs for SS groups.

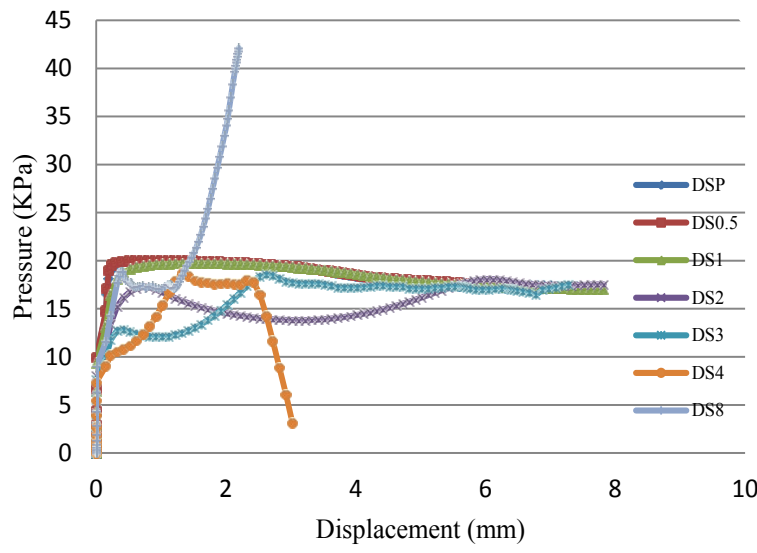

Figure 9: Load-displacement graphs for DS groups. is occurred in the SS4 and DS4 which present initial buckling to the perfect model are $-196.52 \%$ and $-159.89 \%$ for SS4 and DS4, respectively. Table 9 shows the $8 \mathrm{t}$ type imperfection. It acts as a stiffener than to the other imperfections. However, the imperfection depth is greater; the collapse load is decreasing until $4 \mathrm{t}$ type imperfection. After that, the collapse load is suddenly increased. Thus, the models have a big imperfection effect such as a stiffener. Conversely, all models showed the post-buckling phenomenon, while after initial buckling a length path obtained, until the collapse occurred by buckling. For example, in the SS8 model, the initial buckling load is $15.10 \mathrm{KPa}$, and the collapse load is $83.70 \mathrm{KPa}$. The collapse load is 4.7 times greater than the initial buckling load. Table 9 shows the $8 \mathrm{t}$ type imperfection acts as a stiffener more than to the other ones.

Figures 10 and 11 show the buckling effect started from the imperfection located and continued by the cylindrical shell. Figures show, which $\vee$ and $\wedge$ shapes causes lift the edge, and end of analysis. The $8 \mathrm{t}$ type imperfection models are resisted against buckling as seen in Figures 10 and 11.

\section{Non-linear analysis of the ST and DT groups of models with the ratio of $t / R$ equal to 0.002}

Table 10 presents the initial buckling and collapse loads comparison according to the Donnell theory. The obtained initial buckling and the collapse load of the Riks analysis is $25 \%$ to $35 \%$, and $30 \%$ to $36 \%$ greater than the Donnell theory, respectively. Table 10, Figures 12 and 13 present the results of the initial buckling by Riks analysis for ST and DT models. When the imperfection depth increases in the SS4 and DS4 models, negative effects occurred and the imperfection acts as weakener. The initial buckling loads are $-249.09 \%$ and $-175.12 \%$ for the ST4 and DT4 models, respectively. Table 10 shows the $8 \mathrm{t}$ imperfection model, which acts as a stiffener than to other imperfections. However, when the imperfection depth increases, the collapse load decreases until $4 \mathrm{t}$ imperfection model. Then, the models have greater imperfection resulted as a stiffener. The post-buckling phenomenon obtained in all models. After the initial buckling load, a length path occurred until the collapse for all models. For example, in the DT8 model, the initial buckling load and the collapse load is 13.92 $\mathrm{KPa}$, and $50.42 \mathrm{KPa}$, respectively. The collapse load is 3.6 times greater than the initial buckling load. Table 10 shows the $8 \mathrm{t}$ imperfection model, and it acts as a stiffener than to other imperfections. Figures 14 and 15 show the buckling effect, which $\vee$ and $\wedge$ shapes cause lift the edge and end of analysis. The $8 \mathrm{t}$ imperfection models are stabil and resistant against buckling, as seen in Figures 14 and 15.

\section{Non-linear analysis of all groups with $t / R=0.0016$ and $t /$ $\mathbf{R}=\mathbf{0 . 0 0 2}$}

Whatever the imperfection depth is greater, imperfections act as

\begin{tabular}{|c|c|c|c|c|c|c|c|}
\hline Model & $\begin{array}{c}\text { Initial Buckling } \\
\text { (kPa) (FEA) }\end{array}$ & $\begin{array}{c}\text { Collapse (kPa) } \\
\text { (FEA) }\end{array}$ & $\begin{array}{c}\text { Percent initial buckling } \\
\text { to Perfect }(\%)\end{array}$ & $\begin{array}{c}\text { Percent collapse to } \\
\text { Perfect }(\%)\end{array}$ & $\begin{array}{c}\text { Percent initial } \\
\text { buckling to Eq. } 6(\%)\end{array}$ & $\begin{array}{c}\text { Percent collapse to } \\
\text { Eq. } 6(\%)\end{array}$ & $\begin{array}{l}\text { Post-Buckling Percent } \\
\text { collapse to Initial (\%) }\end{array}$ \\
\hline SSP & 32.38 & 32.6 & -- & -- & 35.58 & 36.01 & 0.67 \\
\hline SS0.5 & 27.95 & 29.7 & -15.85 & -9.76 & -- & -- & 5.89 \\
\hline SS1 & 24.5 & 28.65 & -32.16 & -13.78 & -- & -- & 14.48 \\
\hline
\end{tabular}

Table 9: Results of the non-linear analysis for $t / R$ equal to 0.0016 .

\begin{tabular}{|c|c|c|c|c|c|c|c|}
\hline Model & $\begin{array}{l}\text { Initial Buckling } \\
\text { (kPa) (FEA) }\end{array}$ & $\begin{array}{c}\text { Collapse (kPa) } \\
\text { (FEA) }\end{array}$ & $\begin{array}{c}\text { Percent initial buckling } \\
\text { to Perfect }(\%)\end{array}$ & $\begin{array}{l}\text { Percent collapse } \\
\text { to Perfect }(\%)\end{array}$ & $\begin{array}{c}\text { Percent initial buckling } \\
\text { to Eq. } 6(\%)\end{array}$ & $\begin{array}{l}\text { Percent collapse } \\
\text { to Eq. } 6(\%)\end{array}$ & $\begin{array}{l}\text { Post-Buckling Percent } \\
\text { collapse to Initial (\%) }\end{array}$ \\
\hline STP & 50.05 & 51.78 & -- & --- & 34.46 & 36.44 & 3.34 \\
\hline ST0.5 & 41 & 46.5 & -22.07 & -11.35 & --- & --- & 11.83 \\
\hline ST1 & 34.3 & 42.985 & -45.92 & -20.46 & --- & --- & 25.32 \\
\hline
\end{tabular}

Table 10: Results of the non-linear analysis for $t / R$ equal to 0.002 . 


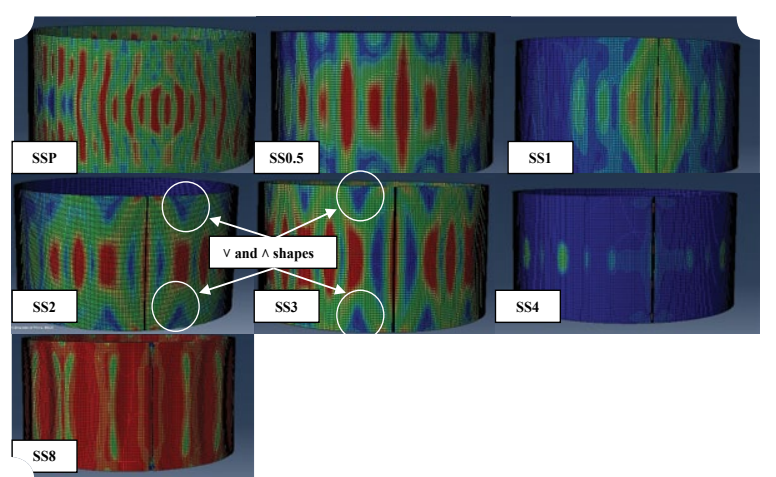

Figure 10: The Riks method of analysis for SS models.

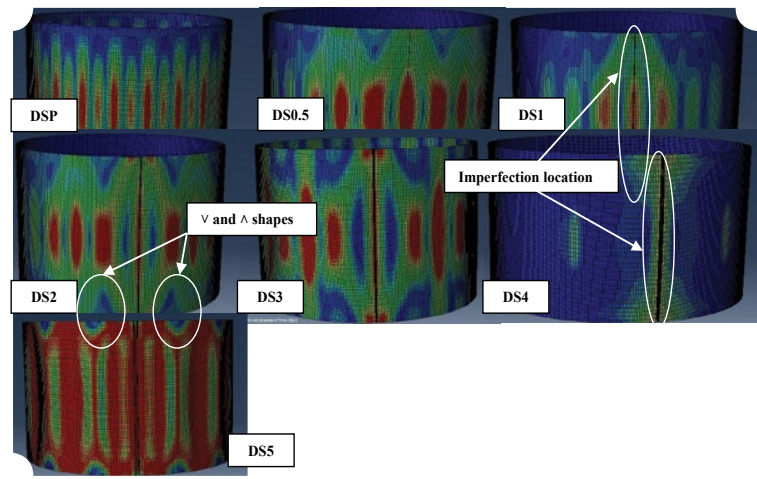

Figure 11: The Riks method of analysis for DS models.

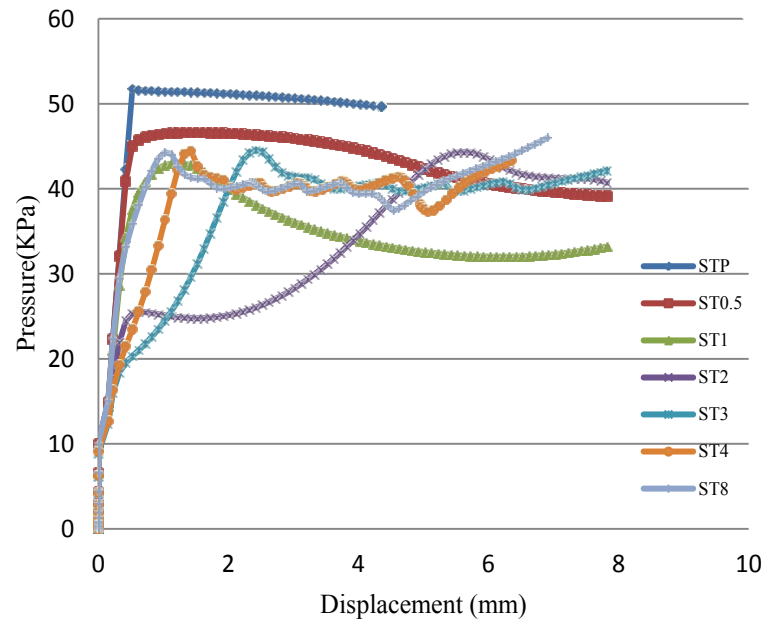

Figure 12: Load-displacement graphs for ST groups.

weakeners until the $4 \mathrm{t}$ imperfection. It afterwards acts as a stiffener in the other three groups. The weakest effect occurred in the $4 \mathrm{t}$ imperfection model from all groups. When the height of the cylinder increased, the buckling load capacity is decreased in each group. For example, the initial buckling load of the STP model is equal to $50.4 \mathrm{KPa}$. The initial buckling load of DTP model is equal to $29.30 \mathrm{KPa}$ for variable heights. When the thickness of cylinder increased, the buckling load capacity is increased in each group. For example, the initial buckling of the STP model is equal to $19.05 \mathrm{KPa}$, while the initial buckling load of DTP is equal to $29.30 \mathrm{KPa}$ with same thickness. The nonlinear buckling load can be obtained by multiplying with 1.36 the results from the Donnell theory for $\mathrm{t} / \mathrm{R}=0.002$ and $\mathrm{t} / \mathrm{R}=0.0016$ models.

There is post-buckling phenomenon and a length path after initial buckling load until the collapse in all models. The collapse load is 3.6 times greater than the initial buckling for the $\mathrm{t} / \mathrm{R}=0.002$ models and 4.7 times for $\mathrm{t} / \mathrm{R}=0.0016$ models.

The buckling effects started with imperfection locate and continue to the cylindrical shell. Figs showed which $\vee$ and $\wedge$ shapes causes lift the edge and end of analysis also $8 \mathrm{t}$ imperfection models are stability and resistant to buckling.

\section{Discussion}

\section{The ABAQUS analyses and experimental results of Fatemi et al.s work}

In 2013, the authors have conducted tests on SS, DS, ST and DT models with perfect, the $4 \mathrm{t}$ and $8 \mathrm{t}$ imperfection models [5] and compared the results with ABAQUS models (Table 11). It should be noted that all models were supported in ABAQUS models, while all models were supported in which a radial constraint at the edges was the only boundary condition in experimental models.

Table 11 presents the results of the buckling loads from Riks analysis and experimental tests [5] of Fatemi et al.'s work. The

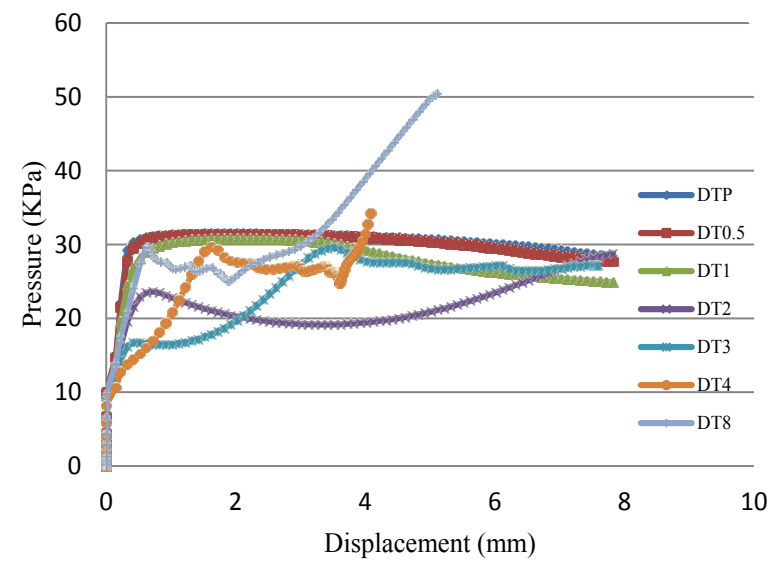

Figure 13: Load-displacement graphs for DT groups.

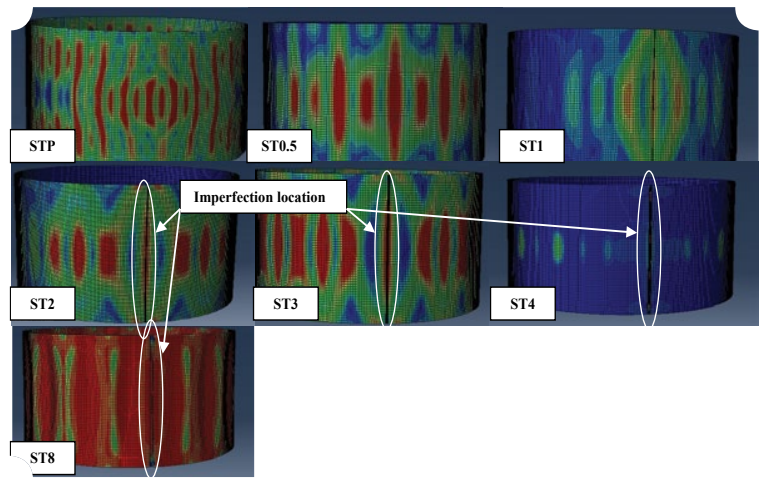

Figure 14: The Riks method of analysis for ST models. 
boundary condition has many effects in buckling loads and number of circumferential waves. Table 11 shows the models with simple support, which have been greater buckling loads than the models considered as simply supported with a radial constraint at the edges. Within the ABAQUS analyses, the simple support with a radial constraint at the edges in experimental were $-1 \%$ to $60 \%$, and the models with simple support have a greater number of circumferential waves than models considered with a radial constraint at the edges. The number of circumferential waves obtained from ABAQUS analyses and experiments, the number of waves were between $33 \%$ and $67 \%$.

Figure 16 of the experimental model is the same as (Figures 4-7, 10, $11,14,15)$. As seen, the buckling effect is started with the imperfection

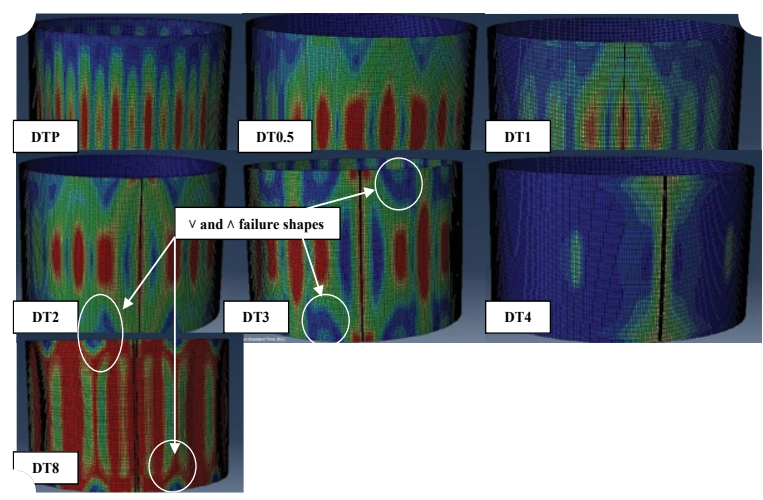

Figure 15: After images displaying the Riks method of analysis for DT models.

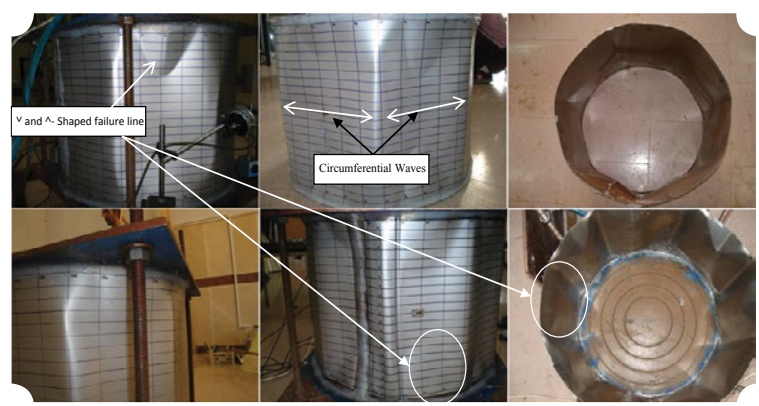

Figure 16: Post-buckling behavior torsion $\vee$ and $\wedge$ shaped failure mode for experimental models. located and continued to the cylindrical shell. The failure shapes of cylindrical waves are the same as $\vee$ and $\wedge$ which $\vee$ and $\wedge$ failure shapes cause lift of the edge and end of analysis or tests [5].

\section{Geometrical imperfections tolerated by the standards}

International codes (such as Eurocode 3, ECCS and DIN 188004) for designing thin-walled shells simply limit the permitted deformations and disturbances during the welding and construction of conical shells (Table 4). Various methods proposed for measuring the magnitude of the initial imperfection depth on the shell's skin in the longitudinal direction include the following:

$\mathrm{l}_{\mathrm{g}}=4(\mathrm{r} / \mathrm{t})^{0.5}$ $3\left[12^{\mathrm{g}}\right]$

$l_{\mathrm{g}}=25 \mathrm{t} \leq 500 \mathrm{~mm}$ at welds for prENV 1993-1-6 (2007): Eurocode

$l_{\mathrm{r}}=4(\mathrm{r} / \mathrm{t})^{0.5} \leq 0.95$ times the distance of the welds

$l_{\mathrm{r}}=25 \mathrm{t}$ at welds for ECCS (2008) [13]

$1_{\mathrm{mx}}=4(\mathrm{r} / \mathrm{t})^{0.5} \leq 2000 \mathrm{~mm}$

$l_{\mathrm{mx}} \leq 500 \mathrm{~mm}$ at welds for DIN 18800 [14]

In these equations, $r$ is the middle surface of the conical shell, $t$ is the thickness of the cone and $l_{m x}, l_{r}$ and $l_{g}$ are all the longitudinal imperfections created circumferentially. The $\mathrm{mx}, \mathrm{r}$ and $\mathrm{g}$ indexes in different codes represent the same length in various forms. Table 12 demonstrates the exact location of this dimension. In the present study, the size of the dent $t_{v}$ and the length of the curve $l_{m Q}$ were designed and created with precise tools, so there is no need to compute the limitations of the above-mentioned formulas.

The values of $\mathrm{t}_{\mathrm{v}}$ for the $0.5 \mathrm{t}, 1 \mathrm{t}, 2 \mathrm{t}, 3 \mathrm{t}, 4 \mathrm{t}$ and $8 \mathrm{t}$ models, where $\mathrm{t}$ is the thickness of the shell, were $0.25 \mathrm{~mm}, 0.5 \mathrm{~mm}, 1 \mathrm{~mm}, 1.5 \mathrm{~mm}, 2 \mathrm{~mm}$ and $4 \mathrm{~mm}$ for $\mathrm{t}=0.5$ and were $0.3 \mathrm{~mm}, 0.6 \mathrm{~mm}, 1.2 \mathrm{~mm}, 1.8 \mathrm{~mm}, 2.4 \mathrm{~mm}$ and $4.8 \mathrm{~mm}$ for $\mathrm{t}=0.6$, respectively. The values of $\mathrm{l}_{\mathrm{mQ}}$ related to $2 \mathrm{t}, 4 \mathrm{t}, 8 \mathrm{t}, 12 \mathrm{t}$, $16 \mathrm{t}$ and $32 \mathrm{t}$ were $1 \mathrm{~mm}, 2 \mathrm{~mm}, 4 \mathrm{~mm}, 6 \mathrm{~mm}, 8 \mathrm{~mm}$ and $16 \mathrm{~mm}$ for $\mathrm{t}=0.5$ and were $1.2 \mathrm{~mm}, 2.4 \mathrm{~mm}, 4.8 \mathrm{~mm}, 7.2 \mathrm{~mm}, 9.6 \mathrm{~mm}$ and $19.2 \mathrm{~mm}$ for $\mathrm{t}=0.6$, respectively. The computation of $\mathrm{t}_{\mathrm{v}}$ and $\mathrm{l}_{\mathrm{mQ}}$ reveals that the specimen values far exceeded the amounts allowed by codes; in such cases, the structure cannot be used.

Calculation of the $\mathrm{t}_{\mathrm{v}}$ and $\mathrm{l}_{\mathrm{mQ}}$ reveals that the imposed $\mathrm{t}_{\mathrm{v}}$ exceeds the value allowed by the code and the structure should stop functioning. The codes do not refer to destruction of these structures. The Abaqus analyses results show that in some structures, imperfections strengthen the shell and, in some cases, increase the resistance as much as three

\begin{tabular}{|c|c|c|c|c|c|}
\hline Model & $\begin{array}{l}\text { Experimental Collapse load [5] } \\
\text { (kPa) }\end{array}$ & $\begin{array}{l}\text { ABAQUS collapse load } \\
(\mathrm{kPa})\end{array}$ & Experimental waves & $\begin{array}{l}\text { ABAQUS waves } \\
\text { ( linear waves) }\end{array}$ & Percent ABAQUS to Experimental (\%) \\
\hline SCSP & 28.57 & 32.6 & 10 & 16 & 12.28 \\
\hline SCS4 & 27.95 & 27.8 & 10 & 16 & -0.53 \\
\hline SCS8 & 33.975 & 83.7 & 10 & 16 & 59.41 \\
\hline DCSP & 14.125 & 19.95 & 8 & 13 & 29.2 \\
\hline DCS4 & 17.575 & 18.75 & 7 & 13 & 6.3 \\
\hline DCS8 & 17.825 & 42.2 & 9 & 13 & 57.76 \\
\hline SCTP & 38.7 & 51.7 & 10 & 15 & 25.14 \\
\hline SCT4 & 29.3 & 44.47 & 9 & 15 & 34.11 \\
\hline SCT8 & 30.6 & 46 & 10 & 15 & 33.48 \\
\hline DCTP & 18.375 & 31.4 & 8 & 12 & 41.48 \\
\hline DCT4 & 19.7 & 34 & 8 & 12 & 42.06 \\
\hline DCT8 & 20.425 & 50.42 & 9 & 12 & 59.49 \\
\hline
\end{tabular}

Table 11: Comparison between ABAQUS analyses and experimental results of Fatemi's works. 


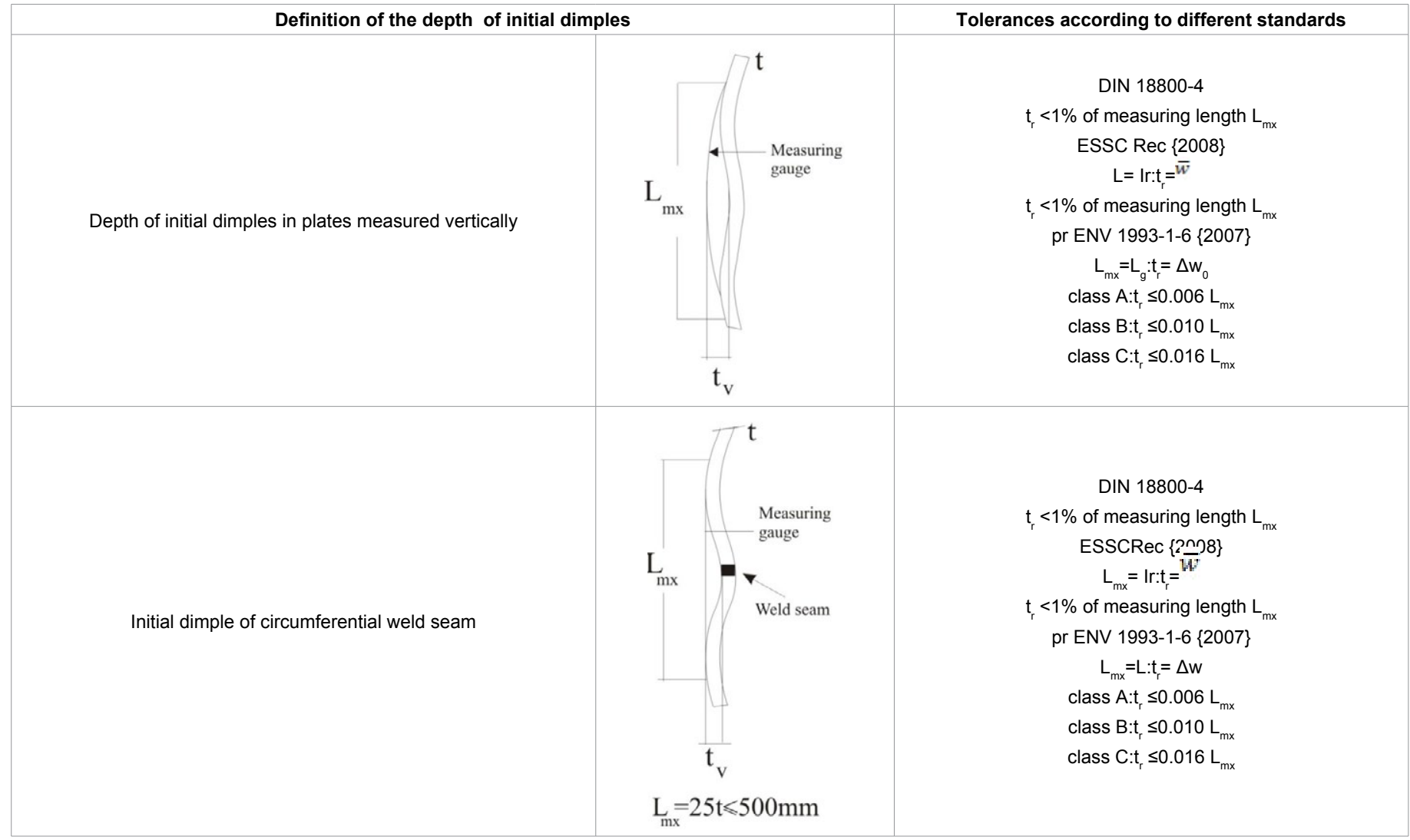

Table 12: Geometric tolerances according to different standards.

times. In these cases, there is no need to stop using these structures and their function should continue with special care. The codes related to thin-walled shells have no references to studies referring to the postbuckling capacities of shells. The codes simply suggest not using such structures. This conclusion requires a great deal of investigation and thought [5].

\section{Conclusion}

This study discusses the buckling behavior of thin-walled conical shells. The 28 models with various imperfections with various amplitudes were loaded under external pressure. All models were analyzed by Abaqus software. The following results were concluded:

a) The number of circumferential waves in buckling analyses can be obtained by adding $5^{\text {th }}$ and $2^{\text {nd }}$ equations.

b) Axial waves are equal to one in all groups. There is always an axial wave in cylindrical shells with longitudinal imperfection.

c) When the imperfection depth is greater, imperfections act as a stiffener in all groups in linear analyses.

d) The height of the cylinder $(\mathrm{H})$ is higher; the buckling load capacity is low in linear analyses.

e) The critical buckling load capacity occurred between the $2 t$ and $3 t$ imperfections, which disappeared in the range of all groups in linear analyses.

f) Whenever the imperfection depth is greater, imperfections act as weakener until the $4 \mathrm{t}$ imperfection, and afterwards act as a stiffener in the three groups in the nonlinear analyses. g) The weakest effect occurred in the $4 \mathrm{t}$ imperfection in all groups in the nonlinear analyses.

h) When the height of the cylinder increased, the capacity buckling load decreased in each group. When the thickness of the cylinder increased, the buckling load capacity increased in each group in nonlinear analyses.

i) The nonlinear buckling load can be obtained from the Donnell theory for $\mathrm{t} / \mathrm{R}=0.002$ and $\mathrm{t} / \mathrm{R}=0.0016$ models, by multiplying the Donnell theory with 1.36 .

j) There is post-buckling phenomenon in all models. The collapse load is 3.6 times greater than the initial buckling load for the $\mathrm{t} / \mathrm{R}=0.002$ models and 4.7 times for $\mathrm{t} / \mathrm{R}=0.0016$ models.

k) The buckling effects started with imperfection located and continued to the cylindrical shell. Figures 10-16 showed which $\vee$ and $\wedge$ failure shapes cause lifting of the edge and end of analysis.

1) The models with simple support have greater number of circumferential waves than models, which considered simply supported with a radial constraint at the edges. Furthermore, the number of circumferential waves from Abaqus analyses and from the experiments was between $33 \%$ and $67 \%$.

m) The codes related to thin-walled shells have no references about post-buckling capacities of shells; the codes simply suggest that such structures should not be used. This conclusion requires a great deal of investigation and thought. 


\section{References}

1. Wintersetter A, Schmit H (2002) Stability of circular cylindrical steel shells under combined loading. Thin-Walled Structures 40: 893-909.

2. Teng JG, Zhao Y, Lam L (2001) Techniques for buckling experiments on steel silo transition junction. Thin-Walled Structures 39: 685-707.

3. Popov AA (2003) Prametric resonance in cylindrical shells: a case study in nonlinear vibration of structural shell. Eng struct 23: 789-990.

4. Ross CTF, Little APF, Adeniyi KA (2005) Plastic buckling of ring-stiffened conical shells under external hydrostatic pressure. Ocean Eng 32: 21-36.

5. Fatemi SM, Showkati H, Maali M (2013) Experiments on imperfect cylindrical shells under uniform external pressure. Thin-Walled Structures 65: 14-25.

6. Showkati H, Ansourian H (1995) Influence of primary boundary conditions on the buckling of Shallow cylindrical shells. Journal of Constructional Steel Research 36: 53-75

7. Pircher M, Berry P, Ding X, Bridge R (2001) The shape of circumferentia weld-induced imperfections in thin-walled steel silos and tanks. Thin-Walled Structures 39: 999-1014

8. Hornung U, Saal H (2002) Buckling loads of tank shells with imperfections International Journal of Non-linear Mechanics 37: 605-621.

9. Schneider W, Brede A (2005) Consistent equivalent geometric imperfections for the numerical buckling strength verification of cylindrical shells under uniform external pressure. Journal of Thin-Walled Structures 43: 175-188.

10. Maali M, Showkati H, Fatemi SM (2012) Investigation of the buckling behavior of conical shells under weld-induced imperfections. Thin-Walled Structures 57: $13-24$

11. Niloufari A, Showkati H, Maali M, Fatemi SM (2014) Experimental investigation on the effect of geometric imperfections on the Buckling and Post-buckling behavior of steel tanks under hydrostatic pressure. Thin-Walled Structure 74 59-69.

12. EN 1993-1-6 (2007) (English): Eurocode 3: Design of steel structures - Part 1-6: Strength and stability of shell structures.

13. Rotter JM, Schmidt H (2008) European Recommendations for Stee Construction: Buckling of Shells (5th edn), ECCS EDR5 European Convention for Constructional Steelwork, Brussels, Belgium.

14. Standard: DIN 18800-4 (2008) Steel structure - Part 4: Stability - Analysis of safety against buckling of shells. 51

15. Tahir, ZR, Mandal, P (2017) Artificial neural network prediction of buckling load of thin cylindrical shells under axial compression. Engineering Structures 152: 843-855.

16. Chena Z, Fanb H, Chenga, J, Jiaoa P, Xua, F, et al. (2018) Buckling of cylindrical shells with measured settlement under axial compression, ThinWalled Structures 123: 351-359.

17. Wang B, Zhu S, Hao P, Bi X, Du K, et al. (2018) Buckling of quasi-perfect cylindrical shell under axial compression: A combined experimental and numerical investigation. International Journal of Solids and Structures 130 : 232-247.

18. Ghazijahani TG, Dizaji, HS, Nozohor J, Zirakian T (2015) Experiments on corrugated thin cylindrical shells under uniform external pressure. Ocean Engineering 106: 68-76.

19. Koiter WT (1945) A translation of the stability of elastic equilibrium. PhD thesis, Technische Hooge School, Delft, The Netherlands.

20. Hübner A, Teng JG, Saal H (2006) Buckling behavior of large steel cylinders with patterned welds. International J Pressure Vessels and Piping 83: 13-26.

21. ABAQUS (2010) Theory and user's manual, Version 6.12.1 